\title{
Soil-microorganism-mediated invasional meltdown in plants
}

\author{
Zhijie Zhang $\odot 1$, Yanjie Liu $\oplus^{2 \bowtie}$, Caroline Brunel $\odot^{3,4}$ and Mark van Kleunen $\oplus^{1,3}$
}

\begin{abstract}
While most alien species fail to establish, some invade native communities and become widespread. Our understanding of invasion success is derived mainly from pairwise interactions between aliens and natives, while interactions among more than two species remain largely unexplored. Here, we experimentally tested whether and how a third plant species, either native or alien, affected the competitive outcomes between alien and native plants through its soil legacy. We first conditioned soil with one of ten species (six natives and four aliens) or without plants. We then grew on these 11 soils five aliens and five natives without competition, or with intra- or interspecific competition. We found that aliens were not more competitive than natives when grown on soil conditioned by other natives or on non-conditioned soil. However, aliens were more competitive than natives on soil conditioned by other aliens (that is, invasional meltdown). Soil conditioning did not change competitive outcomes by affecting the strength of competition between later plants. Instead, soil conditioned by aliens pushed competitive outcomes towards later aliens by affecting the growth of aliens less negatively than that of natives. Microbiome analysis verified this finding, as we showed that the soil-legacy effects of a species on later species were less negative when their fungal endophyte communities were less similar, and that fungal endophyte communities were less similar between two aliens than between aliens and natives. Our study reveals invasional meltdown in multispecies communities and identifies soil microorganisms as a driver of the invasion success of alien plants.
\end{abstract}

\footnotetext{
T
} he accumulation of alien species and their potential threats to biodiversity demand an answer to what determines the invasion success of aliens ${ }^{1-3}$. Charles Elton, in his famous book, posited superior competitive ability as one of the mechanisms ${ }^{4}$. Since then, hundreds of experiments have studied competition between native and alien species, confirming that many successful alien species are indeed more competitive than natives ${ }^{5-7}$. Most studies, however, focused on pairwise interactions ${ }^{8}$ (Fig. 1a, but see refs. ${ }^{9-11}$ for studies of multispecies interactions), although in nature most species interact with multiple species. Moreover, interactions between alien species have also been frequently observed ${ }^{12}$. In many cases, aliens seem to favour other aliens over natives ${ }^{13,14}$, a phenomenon called invasional meltdown ${ }^{15}$. Still, invasional meltdown has so far been studied mainly in pairs of alien species without considering interactions with native species ${ }^{16,17}$. The competitive outcomes between alien and native species in multispecies communities therefore remain unknown.

A major challenge in community ecology is to predict competitive outcomes in multispecies communities (for example, to predict which species will dominate). Many studies suggest that outcomes in multispecies communities can be predicted from two-species systems, by assuming that interactions remain pairwise in all systems $^{18-20}$. For a hypothetical example, consider adding a third species into a two-species community (Fig. 1b). If we knew from previous pairwise experiments that the third species strongly suppresses one of the two species, we would predict that it will indirectly release the other species from competition. Although this bottom-up approach has been supported by several experiments on microorganisms $s^{21,22}$, the effect of one competitor on another (that is, the strength of competition) can be changed by a third species ${ }^{33.24}$ (Fig. 1c,d). For example, it was shown that Skeletonema costatum, a cosmopolitan diatom, does not directly affect the growth of Karenia brevis, a dominant dinoflagellate in the Gulf of Mexico, but it undermines the allelopathic effects of $K$. brevis ${ }^{25}$. This would also lessen the effect of $K$. brevis on other phytoplankton species, and interactions might consequently not always remain pairwise. We therefore need to test how the competitive outcomes between alien and native species are affected by other species explicitly.

Competition occurs through different processes, which makes it challenging to study. The most widely studied process is resource competition $^{26}$, partly because competition for space, food and other resources is the most intuitive. Nevertheless, growing evidence shows that resource use alone cannot always explain the success of alien species ${ }^{27-29}$. Competition can also act through other trophic levels. This so-called apparent competition ${ }^{30}$ has been extensively studied in systems in which plants affect others through shared aboveground herbivores ${ }^{8.9}$. The past two decades have also seen an increased interest in apparent competition mediated by soil microorganisms. More and more studies reveal that plants modify soil microorganisms, with consequences for their own development and for plants that grow subsequently on the soil ${ }^{31-35}$ (a mechanism that we hereafter refer to as a soil-legacy effect).

Studies on soil-legacy effects have opened up new avenues to test mechanisms of plant invasion ${ }^{36}$, such as enemy releas ${ }^{37-39}$ and novelty of aliens ${ }^{40,41}$. On the basis of these mechanisms, we expect that the origin (alien or native) of the third species matters in how it affects competitive outcomes between alien and native species. First, enemy release posits that alien plants are released from their enemies $^{42}$, and therefore soil conditioned by alien plants should accumulate few soil pathogens. Consequently, aliens would free natives that grow later on that soil from pathogens, unless they accumulate pathogens that are highly toxic to natives ${ }^{43}$. However,

'Ecology, Department of Biology, University of Konstanz, Konstanz, Germany. ${ }^{2}$ Key Laboratory of Wetland Ecology and Environment, Northeast Institute of Geography and Agroecology, Chinese Academy of Sciences, Changchun, China, ${ }^{3}$ Zhejiang Provincial Key Laboratory of Plant Evolutionary Ecology and Conservation, Taizhou University, Taizhou, China. ${ }^{4}$ IRD, IPME, Montpellier, France, ${ }^{凶} \mathrm{e}-$ mail: liuyanjie@iga.ac.cn 


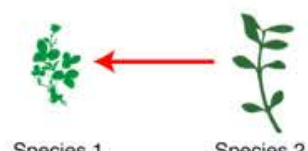

Species 1 b

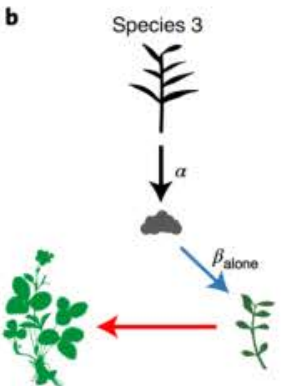

Species 1

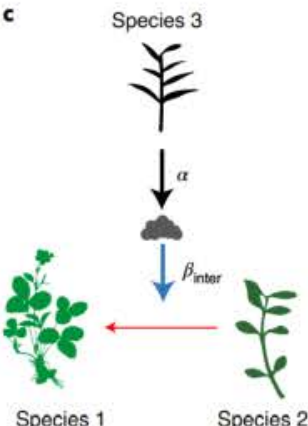

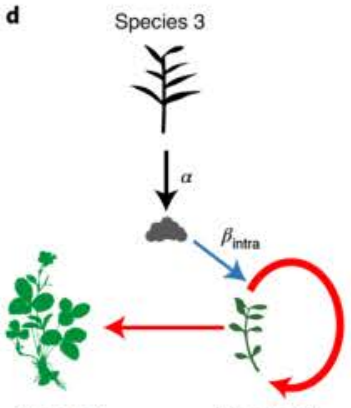

Species 1
Species 2

Fig. 1| Graphical illustration of how a third species can affect competitive outcomes between two species through changes in soil microbial communities. a, In pairwise competition, species 2 suppresses species 1. Consequently, species 2 is more competitive, as indicated by its larger size. $\mathbf{b}$, When the soil microbial communities are modified ( $\alpha$, black arrow), species 3 favours species 1 by suppressing species $2\left(\beta_{\text {alone }}\right)$. Now species 1 is more competitive, as indicated by its larger size. $\mathbf{c}$, Species 3 does not suppress species 2 but favours species 1 by lessening the suppression of species 1 by species 2 ( $\beta_{\text {inter }}$ indicated by the thinner red arrow). d, Species 3 favours species 1 by increasing the suppression of species 2 by itself ( $\beta_{\text {intra }}$ indicated by the curved red arrow). The overall effect of species 3 on competitive outcomes between species 1 and $2, \beta_{\text {tota, }}$ is the net effect of $\beta_{\text {alone }} \beta_{\text {inter }}$ and $\beta_{\text {intra. }}$. Species 1 image adapted from phylopic.org.

if aliens grow later on the soil, they might not be affected, because they are already released from pathogens. Following this logic, soil conditioned by aliens would subsequently favour natives over aliens. Second, natives are familiar to (that is, coevolve with) each other, whereas aliens and natives are novel to each other (that is, they did not coevolve) $)^{41,44}$. Natives should therefore accumulate soil pathogens that are more likely shared with other natives than with aliens. Following this logic, soil conditioned by natives would subsequently favour aliens over natives. Whether these two expectations hold remains unknown.

As the competitive outcomes between alien and native plants in multispecies communities remain unclear, we tested them with a large multispecies experiment (Fig. 2). We first conditioned soil with one of ten species (six natives and four aliens; Supplementary Table 1) or, as a control, without plants. Then, on each of these 11 soils, we grew five alien and five native test species (Supplementary Table 1) without competition or with intraspecific or interspecific competition, using all pairwise alien-native combinations. To assess the potential role of microorganisms, we also analysed the relationship between soil communities and soil-legacy effects. We addressed the following questions: (1) Do soil-conditioning species (third species) affect the competitive outcome between later

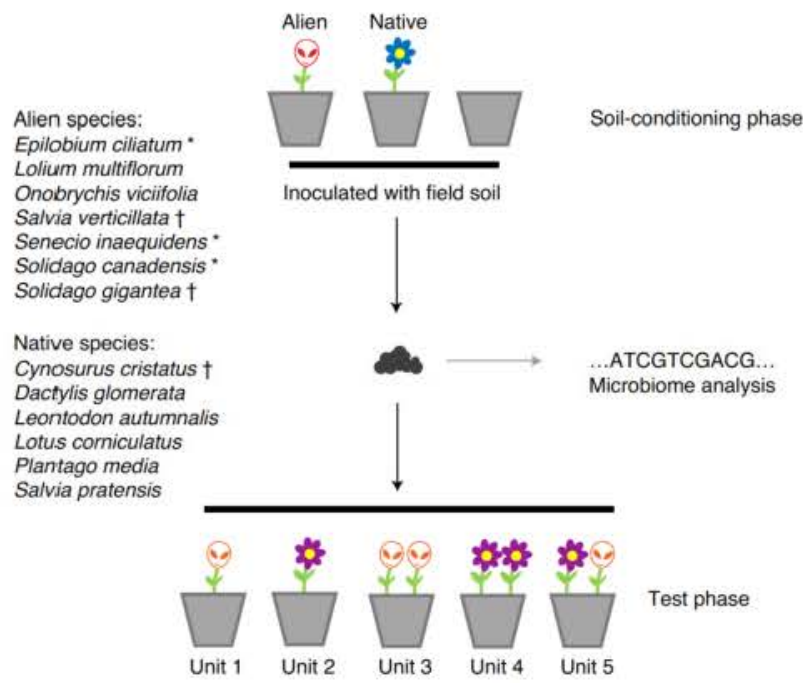

Fig. 2 | Graphical illustration of the experimental design. In the

soil-conditioning phase, the soil was conditioned by one of ten species (either alien or native) or without plants. The test species were then grown on each of these 11 soils alone or with intra- or interspecific competition. The soil was sampled after conditioning, and amplicon sequencing was used to assess the microbial communities. Plants grown alone (units 1 and 2) were used to test how the soil-conditioning species affected the growth of the test species ( $\beta_{\text {alone }}$ in Fig. 1). The differences between plants grown in competition (units 3-5) and the ones grown alone were used to test how the soil-conditioning species affected the strength of intra- and interspecific competition ( $\beta_{\text {intra }}$ and $\beta_{\text {inter }}$ ). The aboveground biomass across competition treatments indicated competitive outcomes (that is, aliens are considered more competitive than natives when they had a higher aboveground biomass across units 1-5) and were used to test how the soil-conditioning species affected competitive outcomes $\left(\boldsymbol{\beta}_{\text {total }}\right)$. Species marked with asterisks were used only in the test phase. Species marked with daggers were used only in the soil-conditioning phase. Others were used in both phases.

alien and native test species through soil-legacy effects $\left(\beta_{\text {total }}\right.$, the net effect of $\beta_{\text {alone }}, \beta_{\text {inter }}$ and $\beta_{\text {intra }}$ in Fig. 1), and does the origin (native or alien) of the third species matter? (2) If so, do soil-conditioning species affect competitive outcomes by affecting the growth of the test species $\left(\beta_{\text {alone }}\right)$ or by affecting the strength of competition $\left(\beta_{\text {inter }}\right.$ and $\beta_{\text {intra }}$ )? (3) Does the variation in soil microbial communities among the conditioned soils $(\alpha)$ explain the variation in soil-legacy effects?

\section{Results}

Do soil-conditioning species affect competitive outcomes (that is, differences in biomass production) between alien and native species?. On average, plants produced less aboveground biomass $\left(-67.2 \% ; \chi^{2}=10.31, P=0.001\right)$ on conditioned soil than on non-conditioned soil, and on home soil (that is, soil conditioned by the same plant species) than on away soil $\left(-22.7 \% ; \chi^{2}=4.54\right.$, $P=0.033$; Fig. $3 \mathrm{a}$ and Table 1 ). The biomass of alien and native plants did not significantly differ across soil-conditioning treatments and competition treatments $\left(\chi^{2}=0.083, P=0.774\right.$; Fig. $3 \mathrm{a}$ and Table 1). Compared with non-conditioned soil, conditioned soil did not change the difference in biomass between alien and native plants across competition treatments (Origin $\times$ Soil $_{\text {Non-conditioned/ }}$ Conditioned interaction, $\chi^{2}=1.395, P=0.238$; Fig. $3 \mathrm{a}$ and Table 1$)$. However, when grown on alien soil (that is, soil conditioned by an 

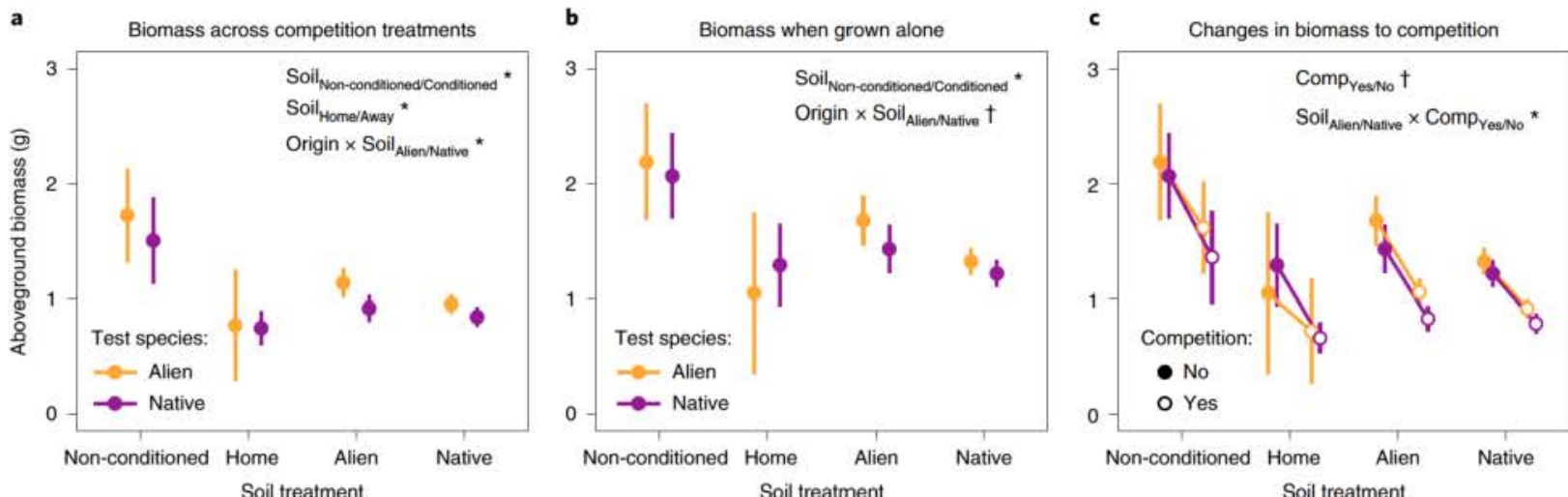

Fig. 3 | Effects of soil-conditioning treatments on aboveground biomass of alien (orange) and native (purple) test species. a, Mean values ( + s.e.m.) were calculated across competition treatments. Alien test species are considered more competitive than natives when they had a higher aboveground biomass. b. Mean values were calculated on the basis of the aboveground biomass of plants grown alone. $\mathbf{c}$. Slopes indicate the strength of competition-that is, the difference in aboveground biomass between plants grown alone (solid dots, the same values as in $\mathbf{b}$ ) and those grown in competition (open dots). For the soil-conditioning treatments, 'non-conditioned' refers to soil that was not conditioned by any plant, 'home' to soil conditioned by the same species as the test species, and 'alien' and 'native' to soils conditioned by other species than the test species, which were alien or native, respectively. The differences in mean values between different soil treatments in $\mathbf{a}, \mathbf{b}$ and $\mathbf{c}$ indicate differences in $\beta_{\text {total }} \beta_{\text {alone }}$ and $\beta_{\text {inter }}$ (or $\beta_{\text {intra }}$ ), respectively. Significant effects $(P<0.05$ ) are marked with an asterisk, and marginally significant effects $(0.05 \leq P<0.1)$ are marked with a dagger. See Fig. 1 for details on $\beta$ s.

alien plant), alien plants produced significantly more aboveground biomass $(+18.2 \%)$ than native plants, whereas on native soil, this difference was smaller $\left(+9.9 \%\right.$; Origin $\times$ Soil $_{\text {Alien/Native }}$ interaction, $\chi^{2}=4.74, P=0.029$ ). This indicates that soil conditioned by an alien plant pushed the competitive outcome more strongly towards later aliens than soil conditioned with a native plant.

Do soil-conditioning species affect growth or the strength of competition?. For the subset of plants grown alone (competition free), aboveground biomass was lower on conditioned soil than on non-conditioned soil $\left(-59.8 \% ; \chi^{2}=13.38, P<0.001\right.$; Fig. $3 \mathrm{~b}$ and Supplementary Table 4$)$. The competition-free plants also tended to produce less biomass on home soil than on away soil (Fig. 3b). This effect was not significant for aboveground biomass but was marginally significant for belowground biomass $\left(-15.0 \% ; \chi^{2}=2.93\right.$, $P=0.087$; Fig. 3b and Supplementary Fig. 2). Averaged across all soil-conditioning treatments, alien and native competition-free plants did not differ in biomass production $\left(\chi^{2}=0.025, P=0.875\right)$. However, aliens achieved more aboveground biomass $(+17.3 \%)$ than natives on alien soil, whereas on native soil, this difference was smaller ( $+8.5 \%$; Fig. 3 b and Supplementary Table 4$)$. Although this difference was only marginally significant for aboveground biomass $\left(\chi^{2}=2.90, P=0.088\right)$ and belowground biomass $\left(\chi^{2}=3.23\right.$, $P=0.072)$, it was significant for total biomass $\left(\chi^{2}=4.56, P=0.033\right.$; Extended Data Fig. 1). This result indicates that soil conditioned by an alien plant reduced the growth of later alien plants to a lesser degree than the growth of later native plants.

Competition reduced aboveground biomass $(-35.1 \%$; $x^{2}=3.74, P=0.053$; Fig. $3 c$ and Table 1) and was more intense when the test plants were grown on alien soil than on native soil $\left(-39.3 \%\right.$ versus $-33.0 \% ; \chi^{2}=4.85, P=0.028$; Fig. $3 \mathrm{c}$ and Table 1$)$. However, the strength of competition was not affected by the other soil-conditioning treatments. Alien and native test species did not differ in their biomass responses to competition $\left(\chi^{2}=0.25\right.$, $P=0.618$ ), and this finding holds for each of the soil-conditioning treatments. We also found that intra- and interspecific competition did not differ in strength $\left(\chi^{2}=0.80, P=0.373\right)$, and this finding holds for alien and native test species and for each of the soil-conditioning treatments (Fig. $3 \mathrm{c}$ and Table 1).
Does the variation in soil microbial communities explain the variation in soil-legacy effects?. Overall, the presence of plants significantly modified the composition of soil bacterial and fungal communities (Extended Data Fig. 2 and Supplementary Tables 5 and 6). Moreover, alien and native plant species modified the composition of bacterial and fungal communities differently (Extended Data Fig. 2). However, neither the presence of plants nor the origin of plants significantly affected the relative abundance of fungal pathogens or the diversities of bacteria, all fungi and the subset of fungal pathogens (Extended Data Fig. 3 and Supplementary Tables 7 and 8). Further analyses showed that the variation in relative abundance of fungal pathogens and diversity of bacteria, all fungi and fungal pathogens did not significantly explain the variation in soil-legacy effects of soil-conditioning species on test species that were grown alone ( $\beta_{\text {alonc }}$; Extended Data Fig. 4 and Supplementary Tables 11 and 12). This holds for both native and alien test species.

The compositions of soil bacterial communities were less similar (that is, bluer squares in Fig. 4) between individual plants of different species than between plants of the same species $\left(\chi^{2}=4.31\right.$, $P=0.038$; Fig. 4a,e and Supplementary Table 9). Although this was not the case for fungal communities, their dissimilarity depended on the origins of the species in the between-species combination (Fig. $4 \mathrm{~b}-\mathrm{d}, \mathrm{f}-\mathrm{h}$ and Supplementary Table 9). Specifically, the compositions of fungal communities as a whole and of the subset of fungal endophytes were less similar between two alien plant species than between an alien and a native species (fungi, $\chi^{2}=4.00, P=0.045$; fungal endophytes, $\chi^{2}=12.11, P=0.001$ ). In addition, the compositions of fungal endophyte communities were less similar between an alien and a native species than between two natives $\left(\chi^{2}=10.53\right.$, $P=0.001 ;$ Fig. $4 \mathrm{~d}, \mathrm{~h})$.

For the subset data on dissimilarities of soil communities between soil-conditioning and test species, we found that the variation in dissimilarity of fungal endophytes (mainly the pathogenic ones) significantly explained the variation in soil-legacy effects $\left(\beta_{\text {alone }}\right)$. Specifically, the legacy effect of soil-conditioning species on test species grown alone $\left(\beta_{\text {alone }}\right)$ became less negative as their fungal endophyte communities became less similar $\left(\chi^{2}=7.49, P=0.006\right.$; Fig. $5 \mathrm{~d}$ and Supplementary Table 13). The same pattern was found for pathogenic fungal endophytes, but not for non-pathogenic 


\begin{tabular}{|c|c|c|}
\hline & $x^{2}$ & $P$ \\
\hline Transplanting date & 12.815 & $<0.001^{*}$ \\
\hline Soil Non-conditioned/Conditioned $_{\text {. }}$ & 10.306 & $0.001^{*}$ \\
\hline Soil ${ }_{\text {Home/Away }}$ & 4.535 & $0.033^{*}$ \\
\hline Soil $_{\text {Alien/Native }}$ & 0.107 & 0.744 \\
\hline 0 & 0.083 & 0.774 \\
\hline Compres/No $_{\text {Y }}$ & 3.738 & $0.053 i$ \\
\hline Comp intra/inter & 0.795 & 0.373 \\
\hline O $\times$ Soil $_{\text {Nan-conditioned/Conditioned }}$ & 1.395 & 0.238 \\
\hline OXSoil $\left.\right|_{\text {Home/Away }}$ & 1.669 & 0.196 \\
\hline $\mathrm{O} \times$ Soil $_{\text {Alien/Native }}$ & 4.741 & $0.029^{*}$ \\
\hline Soil $_{\text {Non-conditioned/Canditioned }} \times$ Comp $_{\text {Yes/No }}$ & 0.956 & 0.328 \\
\hline Soil $_{\text {Non-conditioned/Conditioned }} \times \mathrm{Comp}_{\text {Intra/nter }}$ & 0.176 & 0.675 \\
\hline Soil $_{\text {Home/Awas }} \times$ Comp $_{\text {Yes/No }}$ & 0.121 & 0.728 \\
\hline Soil $_{\text {Home/Away }} \times$ Comp $_{\text {intra/minter }}$ & 2.273 & 0.132 \\
\hline Soil $_{\text {Alien/Native }} \times$ Comp $_{\text {Yes/No }}$ & 4.846 & $0.028^{*}$ \\
\hline Soil $\left.\right|_{\text {Alien/Native }} \times$ Comp Intra/ntinter & 0.321 & 0.571 \\
\hline $\mathrm{O} \times \mathrm{Comp}_{\text {Yes } / \mathrm{NO}_{0}}$ & 0.249 & 0.618 \\
\hline OXComp Intra/later & 0.371 & 0.542 \\
\hline $\mathrm{O} \times$ Soil $_{\text {Non-conditioned/Conditioned }} \times \mathrm{Comp}_{\mathrm{Yes} / \mathrm{No}}$ & 0.511 & 0.475 \\
\hline O $\times$ Soil $_{\text {Non-conditioned/Conditioned }} \times$ Comp Intra/lnter & 0.001 & 0.972 \\
\hline O $\times$ Soil $_{\text {Home/Away }} \times$ Comp $_{\text {Yes } / \text { No }}$ & 1.725 & 0.189 \\
\hline O $\times$ Soil $_{\text {Home/Away }} \times$ Comp $_{\text {Intra/inter }}$ & 0.156 & 0.693 \\
\hline $\mathrm{O} \times$ Soil $_{\text {Alien/Native }} \times$ Comp $_{\text {Yes } / \text { No }}$ & 0.197 & 0.657 \\
\hline O $\times$ Soil $_{\text {Alien/Native }} \times$ Comp $_{\text {Intra/linter }}$ & 0.000 & 0.990 \\
\hline Random effects & s.d. & \\
\hline Family (focal test) & 0.165 & \\
\hline Species (focal test) & 0.199 & \\
\hline Family (competitor test) & 0.065 & \\
\hline Species (competitor test) & 0.076 & \\
\hline Family (soil) & 0.038 & \\
\hline Species (soil) & 0.031 & \\
\hline Residual & 0.187 & \\
\hline
\end{tabular}

fungal endophytes (Extended Data Fig. 5e,f). In addition, the legacy effect $\left(\beta_{\text {alone }}\right)$ became less negative as fungal endophyte communities became less similar between soil-conditioning and test species, though this relationship was marginally significant $\left(\chi^{2}=2.78\right.$, $P=0.096$; Fig. $5 \mathrm{a}$ ). For the other groups of microbiota (that is, fungi overall and fungal pathogens), the soil-legacy effect was not significantly correlated with the dissimilarity of soil communities (Fig. 5b,c).

\section{Discussion}

We found that when grown on soil that was not conditioned by plants, alien and native plants produced similar biomasses across competition treatments. The same was true on soil that was conditioned by plants. This indicates that overall, the naturalized aliens in our study were not more competitive than natives, and that the presence of soil-conditioning species did not change this competitive outcome. However, the origin of the conditioning species matters: on soil conditioned by aliens, aliens produced more biomass than natives and thus were more competitive. The analysis of the biomass of plants grown alone (without competition) indicated that conditioning by aliens changed the competitive outcomes by affecting the growth of aliens less negatively than that of natives, rather than affecting the strength of competition between plants (summarized in Extended Data Fig. 6). Our analysis of soil microbiomes revealed that the legacy effect of soil-conditioning species on test species became less negative as their fungal endophyte communities became less similar, and that fungal endophyte communities were less similar between two aliens than between aliens and natives. This suggests that the less negative effect of conditioning by aliens on other aliens is partly driven by a lower chance of spillover of fungal endophytes between aliens.

Invasional meltdown in a multispecies context. The similar aboveground biomass of aliens and natives on soil that was not conditioned or was conditioned by native plants indicates that on those soils aliens are not more competitive than natives. This result is in line with the recent finding that alien and native species do not differ in their competitive abilities if both of them are widespread and abundant species ${ }^{\gamma}$, as was the case in our study. However, on soil conditioned by aliens, aliens were more competitive than natives. This finding supports the idea of invasional meltdown ${ }^{5,15,16}$ and partly explains the frequent co-occurrence of alien species ${ }^{12}$. So far, over 13,000 plant species have become naturalized outside their natural ranges ${ }^{5,46}$, and in some regions more than half of the flora consists of naturalized alien species ${ }^{47}$. These numbers are still increasing ${ }^{48}$, which means that interactions between alien species are likely to become more and more frequent. Our findings indicate that the relative facilitation between aliens, mediated by soil microorganisms, may accelerate the naturalization of aliens and their competitive impacts on natives.

Still, alien plants may not increase their abundance indefinitely, because intraspecific competition is generally stronger than interspecific competition ${ }^{49}$. We nevertheless did not find a difference between the strengths of intra- and interspecific competition. Probably, resource competition was weak in our study because we fertilized the plants regularly. It is worth noting, however, that plants grew worse on home soil than on away soil in our study. This indicates that intraspecific apparent competition (soil-microorganism-mediated intraspecific competition) was stronger than interspecific apparent competition. Consequently, alien plants were still self-limited. However, alien plants would gain an advantage if they were less limited by intraspecific apparent competition than natives were, which was supported by many studies ${ }^{32}$ but not ours. One possible reason for this discrepancy is the low statistical power in our study. Only two of the five alien test species were grown on home soil, as we had partly different species in the soil-conditioning and test phases. Another reason could be that we used successful native species (that is, widespread and locally abundant). Their intraspecific apparent competition might be weaker than for less successful native species ${ }^{50}$ and thus similar to that of the successful aliens.

It is debated in ecology whether it is possible to predict competitive outcomes in multispecies communities solely on the basis of pairwise interactions. The results of our experiment suggest that this indeed is possible. For example, from the data on plants that were grown alone, which tested pairwise interactions between soil-conditioning and test species, we showed that alien test species produced more biomass than natives on soil that had been conditioned by aliens. This finding still holds when we also included the data on plants that were grown with competition to assess competitive outcomes in multispecies communities. Moreover, the soil-conditioning species rarely changed the strength of 


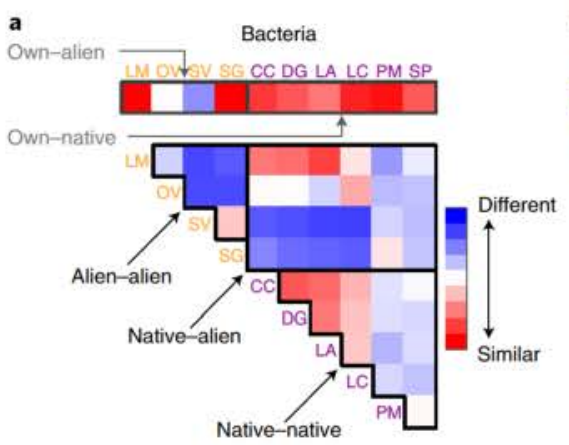

e

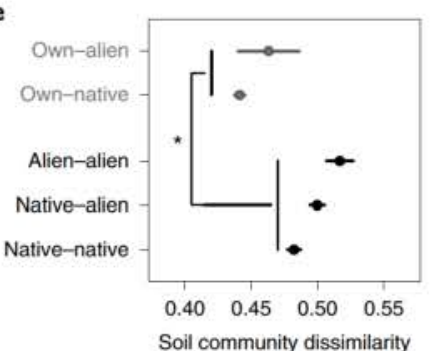

b

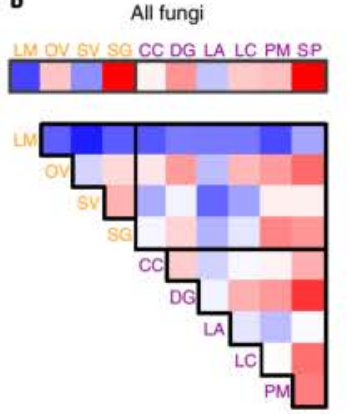

f

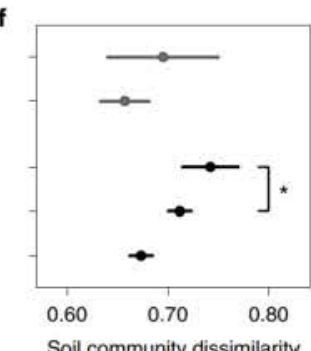

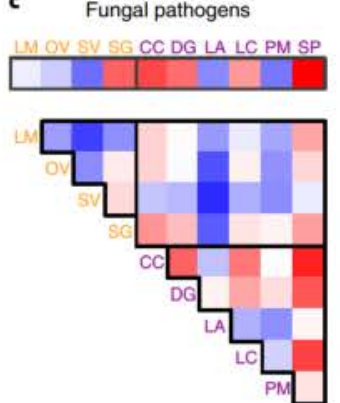

g

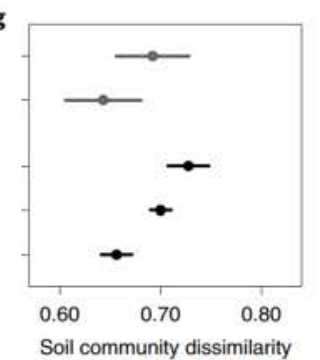

d

Fungal endophytes
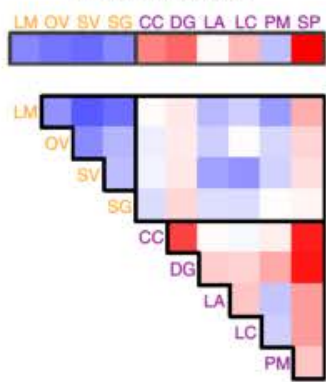

h

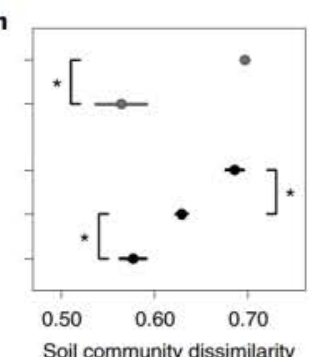

Fig. 4 | Dissimilarities of soil microbial communities within and between plant species. $\mathbf{a}-\mathbf{h}$, Dissimilarities of bacterial communities (a,e), fungal communities (b,f), fungal pathogen communities $(\mathbf{c}, \mathbf{g})$ and fungal endophyte communities (d,h). The upper panels (a-d) show the heat maps of community dissimilarities of all within-species (top horizontal bars) and between-species combinations (triangular matrices), which are divided into five categories (own-alien, own-native, alien-alien, native-alien and native-native) with black borders. The labels at the top and along the diagonal provide abbreviations of the species names (the full names are in Supplementary Table 1) of aliens (orange) and natives (purple). The colours in the heat maps represent the relative dissimilarities, with the darkest blue hue representing the highest dissimilarity. The lower panels (e-h) show the mean values ( \pm s.e.m.) of each of the five categories. Significant differences between categories are indicated with an asterisk (that is, $\alpha$ in Fig. 1 differs between categories). The category definitions are as follows: own-alien, between individual plants of the same alien plant species; own-native, between plants of the same native species; alien-alien, between plants of different alien species; alien-native, between plants of alien and native species; native-native, between plants of different native species.

competition. When they did, they affected the strength of competition equally for alien and native species and thus did not affect competitive outcomes. This finding echoes those of some other experiments. For example, a phytoplankton experiment by Prince et $\mathrm{al}^{25}$ found that the strength of competition was modified in only two out of the ten species in their study. Friedman et al. ${ }^{22}$ found that competitive outcomes in three-species bacterial communities were predicted by pairwise outcomes with an accuracy of $90 \%$. Therefore, we might in most cases be able to scale up from pairwise interactions to at least three-species interactions.

However, it might be too soon to scale up to systems with more than three species. Friedman et al. ${ }^{22}$ found that pairwise outcomes alone poorly predict outcomes of seven- or eight-species bacterial communities. This could indicate that with increasing diversity, the likelihood increases that the strength of pairwise competition is modified by at least one of the many other species in the community. Future experiments that test competition between alien and native organisms in more diverse communities could shed light on this hypothesis. However, as competition occurs locally ${ }^{51}$, it is unlikely that more than a handful of species compete at the same time. Consequently, we believe that our experiment and results are representative of plant invasions in the real world.

Potential mechanisms underlying invasional meltdown. We did not find evidence for the release of soil enemies ${ }^{52}$. At the end of the soil-conditioning phase, alien and native plant species did not differ in the diversity and relative abundance of fungal pathogens. In addition, variation in the diversity and relative abundance of soil fungal pathogens did not significantly explain the variation in growth of alien and native species in the test phase. This lack of evidence for enemy release contrasts with the findings that enemy release contributed to plant invasion ${ }^{53,54}$, but see ref. ${ }^{55}$. This discrepancy may arise from the incomplete information on the functional roles of bacteria and fungi. The functional roles of bacteria are hard to identify, and over $70 \%$ of the sequence reads of fungi in our study could not be assigned to functional groups using FUNGuild. Alternatively, previous studies focused mainly on aboveground enemies. Belowground microbial enemies are more diverse and far less known, and many of them might be rare or less harmful. Therefore, the diversity and relative abundance of soil pathogens may be less likely to capture the mechanism underlying the soil-legacy effect than the actual identities of the pathogens. Indeed, we found that alien and native plants modified the composition of soil microbial communities in different ways (Supplementary Table 5). This suggests that the soil-legacy effect is mediated mainly by the community structure of the soil microbial communities and less by the diversity and abundance.

Interestingly, we found that the compositions of fungal endophyte communities were less similar between alien plant species than between aliens and natives, and less similar than between natives. We found a similar pattern when the field-soil inoculate used in the soil-conditioning phase had been sterilized (Extended Data Fig. 7 and Supplementary Table 10). This suggests that the high dissimilarity of fungal endophyte communities between aliens is probably driven by endophytes that were already present in the 

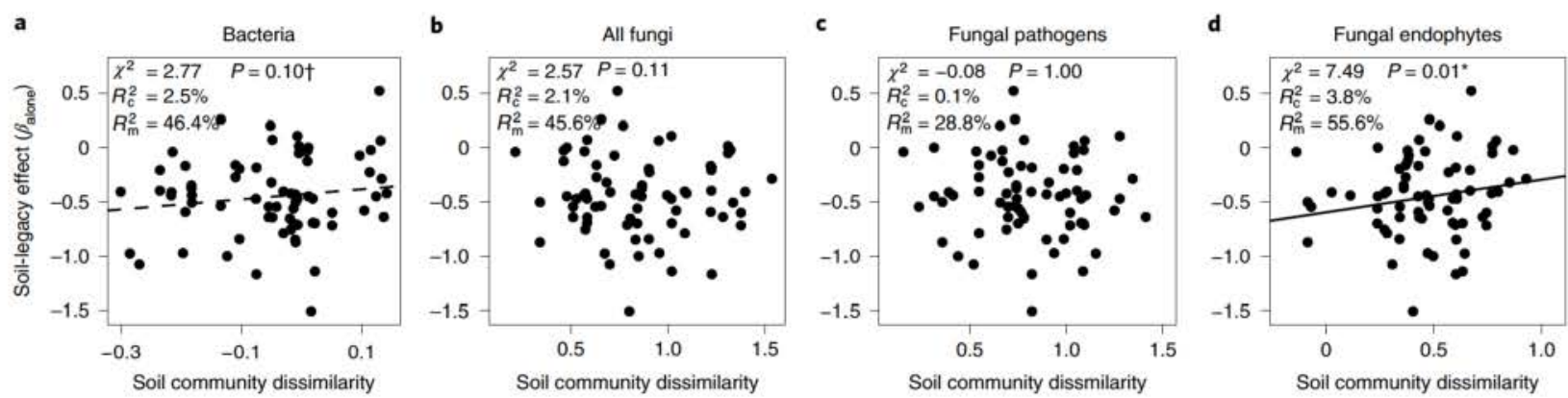

Fig. 5 | Effects of soil-community dissimilarity between soil-conditioning and test species on soil-legacy effects. a, Bacterial communities. b, Fungal communities. c, Fungal pathogen communities. d, Fungal endophyte communities. Negative values of the soil-legacy effect indicate that plants grew worse on conditioned soil than on non-conditioned soil. Soil-community dissimilarity was logit-transformed. Significant effects $(P<0.05)$ of community dissimilarity on soil-legacy effects are indicated with an asterisk (that is, significant effects of $\alpha$ on $\beta_{\text {alone }}$ ), and marginally significant effects ( $0.05 \leq P<0.1$ ) are indicated with a dagger. The chi-squared $\left(\chi^{2}\right)$, conditional $R$ squared $\left(R_{\mathrm{c}}^{2}\right)$ and marginal $R$ squared $\left(R_{\mathrm{m}}^{2}\right)$ values are reported in each panel.

plants before transplanting (for example, as seed microbiota) rather than by those that were in the field-soil inoculum.

There are three potential reasons why the compositions of fungal endophyte communities were less similar between two aliens than between other origin combinations. First, as we found that fungal endophyte communities became less similar with increasing phylogenetic distance between plant species (Supplementary Note 6), it could be that the phylogenetic distance between aliens was higher than between aliens and natives, and also higher than between natives. However, as this was not the case (Supplementary Note 6), this explanation can be discarded. A second potential explanation could be that natives have co-occurred with each other for a longer time and thus share more similar endophytes ${ }^{56}$. A third potential explanation could be that if the alien species brought endophytes with them from their native ranges ${ }^{57}$, these endophytes jumped over to native hosts. Such host shifts of endophytes are more likely to involve native plants than other alien plants, as alien-native interactions are still more common than alien-alien interactions. Regardless of the exact reason, the observed differences in fungal endophyte communities suggest that these communities might play a role in the difference in soil-legacy effects.

In line with this idea, we found that the legacy effect of soil-conditioning species on test species became less negative with decreasing similarity in their fungal endophyte communities. Additional analyses showed that this pattern was driven mainly by pathogenic endophytes, which made up $\sim 40 \%$ of the assigned endophytes (Extended Data Fig. 5e,f). Consequently, when one plant species cultivated very different pathogenic endophyte communities compared with another, endophytes remaining in the soil matrix (for example, root endophytes) were unlikely to infect and negatively affect the other species. This finding, together with the higher difference in fungal endophyte communities between alien plant species than between alien and native plant species, provides an explanation for invasional meltdown. Still, the roles of endophytes are not well understood. Their effects depend on the environment and can range from pathogenic to mutualistic ${ }^{58,59}$. As a result, the legacy effect mediated by endophytes might even change with soil type. More experimental evidence for their role in soil-legacy effects and plant invasions is required. Manipulative studies based on synthetic microbial communities ${ }^{50}$ might shed light on the roles of endophytes in plant competition and invasion success.

\section{Conclusions}

Our results indicate that the accumulation of alien species may be accelerated in the future. This is because aliens could favour other aliens over natives, an effect that is mediated by soil microorganisms (that is, apparent competition). Since Charles Darwin ${ }^{41}$, novelty has been posited as a mechanism underlying invasion success, as it enables aliens to occupy niches that are not used by natives ${ }^{61-63}$. Here, we unveiled another aspect of novelty-novel interactions between aliens. Such novelty could decrease the spillover of pathogenic fungal endophytes between alien plant species. Consequently, alien species in our study suppressed each other less than they suppressed natives, and this could lead to invasional meltdown.

\section{Methods}

Study location and species. We conducted our experiment in the Botanical Garden of the University of Konstanz, Germany $\left(47.69^{\circ} \mathrm{N}, 9.18^{\circ} \mathrm{E}\right)$. We conditioned the soil with one of four plant species that are naturalized aliens in Germany and six plant species that are native to Germany. For these ten soil-conditioning species, we tested their soil-legacy effects on five naturalized alien and five native species (test species; Supplementary Table 1). The soil-conditioning and test species partly overlapped, and in total we used seven alien and six native species. We used multiple species to increase our ability to generalize the results The classification of the species as natives or naturalized aliens in Germany was based on the FloraWeb database ${ }^{\prime s}$. Among the seven alien species, three are native to North America, one to southern Africa and three to other parts of Europe (that is, these three aliens originate from the same continent as the native species; Supplementary Table 1). All 13 species can be locally abundant and are widespread in Germany (that is, they occur in at least $30 \%$ of the regions in Germany; see Supplementary Table 1 for the details). As widespread species are likely to have high spread rates, the alien species can be considered as invasive or probably invasive sensu Richardson et al. ${ }^{60}$. All species occur mainly in grasslands and overlap in their distributions, according to FloraWeb; they are thus very likely to co-occur in nature.

Seeds of the native species and one of the alien species (Onobrychis viciifolia) were purchased from Rieger-Hofmann GmbH. Seeds of the other species were from the seed collection of the Botanical Garden of the University of Konstanz. We initially planned to use the same species in the soil-conditioning and test phases. However, in the soil-conditioning phase, seeds of one of the six native species (Cynosurus cristatus) were contaminated with other species, and the germination success of two aliens (Solidago gigantea and Salvia verticillata) was low. We therefore replaced these three species in the test phase with three alien species (Solidago canadensis, Senecio inaequidens and Epilobium ciliatum).

Experimental set-up. Soil-conditioning phase. From 18 June to 2 July 2018 (Supplementary Table 1), we sowed the four alien and six native soil-conditioning species separately into trays $(10 \mathrm{~cm} \times 10 \mathrm{~cm} \times 5 \mathrm{~cm})$ filled with potting soil (Topferde, Einheitserde Co.). The seeds were not sterilized. Because we wanted the different species to be in similar developmental stages at the beginning of the experiment, we sowed the species at different times (Supplementary Table 1), according to their germination timing known from previous experiments. We placed the trays in a greenhouse under natural light conditions, with a temperature between 18 and $25^{\circ} \mathrm{C}$.

For each species, we transplanted 135 seedlings individually into 1.51 pots. This was done for eight out of ten species from 9 to 11 July 2018. For the other two species, Sa. verticillata and So. gigantea, we transplanted 61 and 115 seedlings, respectively, from 25 July to 12 August (Supplementary Table 1). This was because these two species germinated more slowly and irregularly than foreseen. We also 
added 330 pots that did not contain plants as a control treatment. In a complete design, we would have had 1,680 pots. However, because we had fewer pots of C. cristatus, So. gigantea and $S a$. verticillata, we ended up with 1,521 pots. The substrate that we used was a mixture of $37.5 \%$ (v/v) sand, $37.5 \%$ vermiculite and $25 \%$ field soil. The field soil served as inoculum to provide a live soil microbial community and was collected from a grassland site in the Botanical Garden of the University of Konstanz on 12 June 2018. We removed plant materials and large stones by sieving the field soil through a $1 \mathrm{~cm}$ mesh, and immediately thereafter we stored it at $4^{\circ} \mathrm{C}$ until the transplanting.

After the transplanting, we randomly assigned the pots to positions in four greenhouse compartments $\left(23^{\circ} \mathrm{C} / 18^{\circ} \mathrm{C}\right.$ day/night temperature, no additional light). Each pot sat on its own plastic dish to preserve water and to avoid cross-contamination through soil solutions leaking from the bottoms of the pots. Seedlings that died within two weeks after transplanting were replaced by new ones. All pots, including the ones with and without plants, were watered as needed, randomized twice across the four compartments and fertilized seven times during the soil-conditioning phase with an NPK water-soluble fertilizer (Universol Blue) at a concentration of $1 \% \mathrm{~m} / \mathrm{v}$. From 22 to 26 October 2018, 15 weeks after the start of soil-conditioning phase, we harvested all soil. We cut aboveground biomass at the soil level and freed the soil from roots by sieving it through a $5 \mathrm{~mm}$ mesh. The mesh was sterilized between pots using $70 \%$ ethanol. For the pots in the control treatment, the soil was also sieved through the mesh. We then put the sieved soil of each pot separately into new 11 pots, which were used in the test phase. So, as recommended by Brinkman et al..$^{67}$ and Rinella and Reinhart ${ }^{61}$, we did not pool soil from different pots to ensure the independence of the replicates. The collected aboveground biomass was dried at $70^{\circ} \mathrm{C}$ to constant weight and weighed to the nearest $1 \mathrm{mg}$.

Test phase. From 9 to 18 October 2018, we sowed the five alien and five native test species (Supplementary Table 1) in a similar way as we had done for the species of the soil-conditioning phase. On 29 and 30 October, we transplanted the seedlings into the 11 pots filled with soil from the soil-conditioning phase. Three competition treatments were imposed (Fig. 2): (1) no competition, in which individuals were grown alone; (2) intraspecific competition, in which two individuals of the same species were grown together; and (3) interspecific competition, in which one individual of an alien and one individual of a native species were grown together. We grew all ten species without competition, in intraspecific competition and in all 25 possible native-alien combinations of interspecific competition. For the plants that were grown in non-conditioned soil, we replicated each species without competition 12 times, and each species with intraspecific competition and each interspecific native-alien combination six times. For the plants that were grown on conditioned soil, we had three replicates for each combination of a competition treatment ( 10 without competition, 10 with intraspecific competition and 25 with interspecific competition) and a soil-conditioning species (six native and four alien). Because we had fewer replicates for soil conditioned with C. cristatus, $S \circ$ gigantea and $\mathrm{Sa}$. verticillata, the final design had 1,521 pots (and 2,639 individuals) in the test phase.

We randomly assigned the pots to positions in three greenhouse compartments. Each pot sat on its own plastic dish. Seedlings that died within two weeks after transplanting were replaced with new ones. All plants were watered as needed and fertilized four times during the test phase with the same fertilizer as that in the soil-conditioning phase. The pots were re-randomized across the three compartments on 10 December 2018. On 8 and 9 January 2019, ten weeks after the transplanting, we harvested all aboveground biomass of each plant. For the plants that were grown alone, we washed the belowground biomass free from soil. This could not be done for the plants with competition, as their roots were so tangled that we could not separate them. The biomass was dried at $70^{\circ} \mathrm{C}$ to constant weight and weighed to the nearest $1 \mathrm{mg}$.

Soil sampling, DNA extraction, amplicon sequencing and bioinformatics. From 22 to 26 October 2018, when we harvested the soil from the soil-conditioning phase, we randomly selected six pots of each of the ten soil-conditioning species. For each of these pots, we homogenized the soil and then put a random sample of $10-20 \mathrm{ml}$ in sterile plastic tubes $(50 \mathrm{ml})$. We additionally collected soil from six of the pots without plants. The 66 samples were immediately stored at $-80^{\circ} \mathrm{C}$ until DNA extraction.

Details on the process of DNA extraction, amplicon sequencing and bioinformatics are described in Zhang et $\mathrm{al}^{-1}$. In brief, we extracted DNA from $0.25 \mathrm{~g}$ of each soil sample using the DNeasy PowerSoil Kit (Qiagen), following the manufacturer's protocol. PCR amplifications and amplicon sequencing were then performed by Novogene. The V3-V4 region of bacterial 16S rDNA gene was amplified in triplicate with the universal primers $341 \mathrm{~F} / 806 \mathrm{R}$ (forward primer, 5'-CCTAYGGGRBGCASCAG-3'; reverse primer, 5'-GGACTACNNGGGT ATCTAAT-3'; ref. ${ }^{\text {r) }}$. The ITS2 region of the fungal rDNA gene was amplified in triplicate with the primers specific to this locus (forward primer, $5^{\prime}$-GCATC GATGAAGAACGCAGC- $3^{\prime}$; reverse primer, 5 ' -TCCTCCGCTTATTGATA TGC-3'; ref. ${ }^{71}$ ).

We processed the raw sequences with the DADA2 pipeline, which was designed to resolve exact biological sequences (Amplicon Sequence Variants).
After demultiplexing, we removed the primers and adapter with the cutadapt package ${ }^{2}$. We trimmed the $16 \mathrm{~S}$ sequences to uniform lengths. The sequences were then dereplicated, and the unique sequence pairs were denoised using the dada2 package $e^{7}$. We then merged paired-end sequences, and removed chimaeras. We rarefied the bacteria and fungi to 30,000 and 9,500 reads, respectively, to account for differences in sequencing depth. Three samples with lower reads for bacteria or fungi and two samples with low amplicon concentrations for fungi were excluded from the analyses. For fungi, we assigned the sequences to taxonomic groups using the UNITE ${ }^{-1}$ database. We then identified putative fungal functional groups using the FUNGuild database ${ }^{75}$. Sequence variants assigned to arbuscular mycorrhizal fungi (AMF), plant pathogens and endophytes represented respectively $<0.1 \%$, $11.4 \%$ and $15.7 \%$ of the total read abundance. Sixty-five sequence variants were assigned as both pathogens and endophytes, representing $6.3 \%$ of the total read abundance. This indicates that $\sim 40 \%$ of the assigned endophytes are pathogenic. Because assigned AMF had extremely low abundance and were not detected in 37 out of 62 soil samples, we did not analyse the AMF data.

Statistical analyses. All statistical analyses were done in R version 3.6.1 (ref. ${ }^{76}$ ). We provide the main information for each model in the main text and the details (for example, random effects and variance structure) in Supplementary Note 7.

Analyses of plant performance. To test whether soil-conditioning species affected competitive outcomes between alien and native species $\left(\beta_{\text {total }}\right)$ and the strength of competition ( $\beta_{\text {inter }}$ in Fig. 1c and $\beta_{\text {intrs }}$ in Fig. 1d) in the test phase, we used a linear mixed-effect model (Model.plant.1), as implemented in the nlme package ${ }^{7}$. The model included aboveground biomass of the test plants as the response variable, and the soil-conditioning treatment (none, same species as the test species, native species or alien species), competition treatment (no, intra- and interspecific competition), origin of the test species (native or alien) and their interactions as the fixed effects. A significant interaction between competition treatment and soil-conditioning treatment would indicate that the soil-conditioning treatment affects the strength of competition. A significant three-way interaction of competition treatment, soil-conditioning treatment and origin of the test species would indicate that the soil-conditioning treatment affects the strength of competition of alien and native plants differently. A significant interaction between soil-conditioning treatment and origin of the test species would indicate that the soil-conditioning treatment affects the biomass production of alien and native test species differently, averaged across all competition treatments. In other words, it would indicate that the soil-conditioning treatment affects the competitive outcome between aliens and natives. 'Competitive outcome' here refers to which species will exclude or dominate over the other species at the end point for the community ${ }^{38}$. Most studies infer the competitive outcome by growing the species only in mixture ${ }^{7}$. However, we inferred it from the average of plants without competition, in monocultures and in mixtures. The advantages of this method are that it better mimics the dynamics of species populations across space and time $e^{7,00}$, and it increases the precision of estimating competitive outcomes $s^{78}$.

To test whether soil-conditioning species directly affected the growth of alien and native species ( $\beta_{\text {alme }}$ in Fig. 1b), we analysed the subset of test plants grown without competition with linear mixed-effect models (Model.plant.2). These models included aboveground, belowground or total biomass of test plants as the response variables, and soil-conditioning treatment, origin of the test species and their interaction as fixed effects. For all mixed-effect models, the significance of the fixed effect was assessed with likelihood-ratio tests when comparing models with and without the effect of interest ${ }^{\text {BI }}$.

The soil-conditioning treatment had four levels: (1) the soil was not conditioned by any plant (non-conditioned soil), (2) the soil was conditioned by the same species as the focal test plant (home soil), (3) the soil was conditioned by an alien species (alien soil) or (4) the soil was conditioned by a native species (native soil). We created three dummy variables ${ }^{12}$ to split up these four soil-conditioning treatments into three contrasts to answer the following questions: (1) Does it matter whether the soil was conditioned by plants or not (Soil ${ }_{\text {Non conditaned/Conditioned }}$ ? (2) When the soil was conditioned by plants, does it matter whether the soil was conditioned by the same species as the focal test plant or by a different species (Soil Homeis $_{\text {any }}$ )? (3) When the soil was conditioned by a species different from the focal test plant, does it matter whether the soil was conditioned by an alien or a native species (Soil Alien/Naive $_{\text {) }}$ ? Likewise, for the first model (Model.plant.1), which used data from all competition treatments, we created two dummy variables to split up the three competition treatments (no, intra- and interspecific competition) into two contrasts to answer the following questions: (1) Does it matter whether the test plant was grown with competition (Comp Yens: $)$ ? (2) When the test plant was grown with competition, does it matter whether the competitor belonged to the same species or not (Compintralmet $)$ ?

In some cases of the interspecific competition treatment (103 out of 1,573 pots) the competitor species were the same as the soil-conditioning species. Therefore, these pots are testing a two-species rather than a three-species interaction. However, removing these data points does not affect the results, indicating that our results are robust (Supplementary Table 2). It could be that soil-legacy effects are not due to differences in microbial communities of the soil but due to differences in nutrient availability . For example, larger soil-conditioning plants may have 
left fewer nutrients in the soil, resulting in decreased growth of test species. To account for this, we added aboveground biomass of the soil-conditioning plant as the covariate in Model.plant.1. We found that the aboveground biomass of the test plants decreased with that of the soil-conditioning plant (Supplementary Fig. 1), indicating that nutrient availability might affect test plants. However, adding the covariate did not affect the significance of the other effects (Supplementary Table 3), indicating that our results are robust.

Analyses of the soil microbial community. To test the effect of soil-conditioning species on soil microbial communities ( $\alpha$ in Fig. 1), we used three methods. First, we tested whether the presence of a soil-conditioning plant affected the composition of soil microbial communities and whether this effect depended on the origin of the soil-conditioning species. To do so, we used permutational analysis of variance, as implemented in the adonis function of the vegan package (Model.soil.1). The models included relative read abundances of bacteria or fungi as the response variables and soil-conditioning treatment as the explanatory variable. We split up the three soil-conditioning treatments into two contrast to answer the following questions: (1) Does it matter whether the soil was conditioned by plants or not? (2) When the soil was conditioned by plants, does it matter whether the species is alien or native?

Second, we tested whether alien and native species accumulated putative fungal pathogens, which were identified from FUNGuild, to different degrees. To do so, we used linear mixed models (Model.soil.2) that included the species richness, Shannon diversity or relative abundance of fungal pathogens as the response variable, and soil-conditioning treatments, which were again split up into two contrasts, as the fixed effect. Because some bacteria might be pathogenic and $70 \%$ of the fungi could not be assigned to functional groups on the basis of FUNGuild, we also applied this analysis to species richness and Shannon diversity of all bacteria and fungi.

Third, we analysed how the conditioned soil communities differed (1) among plants from the same alien plant species, (2) among plants from the same native species, (3) among different alien species, (4) among different native species and (5) between alien and native species. To do so, we used linear mixed models (Model.soil.3) and included averaged Bray-Curtis dissimilarities as the response variable, and the five above-mentioned categories of plant combinations as the fixed effect. The Bray-Curtis dissimilarities of bacteria, fungi, fungal pathogens and fungal endophytes were first calculated between all possible pairs of samples and then averaged across replicates to get average values for each within-species pair or between-species pair. As $\sim 40 \%$ of the assigned fungal endophytes are pathogenic, we also analysed pathogenic and non-pathogenic endophytes separately. We split up the five categories of plant combinations into four contrasts to answer the following questions: (1) Are soil communities more similar (or different) when conditioned by the same plant species than by another species? (2) When conditioned by the same species, are soil communities more similar for alien species than for native species? (3) When conditioned by different species, are soil communities more similar between two alien species than between an alien and a native species? (4) When conditioned by different species, are soil communities more similar between an alien and a native species than between two native species? We used heat maps to visualize the community dissimilarities, whose values were mean-centred and then bounded to range from -1 to 1 . This was done with the corrplot package"s

After testing the effect of soil-conditioning species on soil bacterial and fungal communities ( $\alpha$ in Fig. 1), we aimed to identify which aspect of soil microorganisms explained the legacy effect of soil-conditioning species on test plants (that is, which component of $\alpha$ explained the $\beta$ s in Fig. 1). Because the analyses of plant performance revealed that the third species rarely significantly affected the strength of competition (that is, on average, $\beta_{\text {imet }}$ and $\beta_{\text {intrn }}$ did not differ significantly from 0 ), we present the analyses of the effects of $\alpha$ on $\beta_{\text {inter }}$ (or $\beta_{\text {imen }}$ ) in Supplementary Note 5.

We first tested whether the diversity and abundance of potential soil enemies (one aspect of $\alpha$ ) explained the soil-legacy effect on the growth of test plants ( $\beta_{\text {athoe }}$ ) To do so, we used linear mixed models (Model.link.1) and included the soil-legacy effect $\left(\beta_{1}\right)$ as the response variable, and diversities of all soil bacteria, all fungi or the subset of fungal pathogens (or the relative abundance of fungal pathogens) as the fixed effects. Because the enemy release hypothesis predicts that alien species should have less chance to encounter enemies than native species ${ }^{7,55}$, we also added the origin of the test species and their interaction with diversities of soil bacteria, fungi or fungal pathogens (or relative abundance of fungal pathogens) as fixed effects. The soil-legacy effect, $\beta$, was calculated as

$$
\beta_{\text {alone }, i j}=\ln \left(\text { biomass }_{i, j}\right)-\ln \left(\text { biomass }_{i, 0}\right) .
$$

Here, $\ln \left(\right.$ biomass $\left._{i,}\right)$ and $\ln \left(\right.$ biomass $_{i \omega}$ ) are the mean aboveground biomass of test species $i$ when grown without competition (alone) on soil conditioned by species $j$ and on soil not conditioned by plants, respectively. Positive values indicate that soil-conditioning species $j$ improved the growth of test species $i$.

We then tested whether microbial community dissimilarity (another aspect of $\alpha$ ) between the soil-conditioning and test species explained the soil-legacy effect $\left(\beta_{\text {dnex }}\right)$. To do so, we used linear mixed models (Model.link.2) and included the soil-legacy effect, $\beta$, as the response variable, and included Bray-Curtis dissimilarities between soil-conditioning and test species as the fixed effect. Because three out of ten test species were not included in the soil-conditioning phase, we could not calculate the microbial community dissimilarity between them and the soil-conditioning species. Consequently, this analysis was restricted to a subset (that is, 70 out of 100 soil-conditioning species $\times$ test species pairs).

\section{References}

1. van Kleunen, M., Bossdorf, O. \& Dawson, W. The ecology and evolution of alien plants. Annu. Rev. Ecol. Evol. Syst. 49, 25-47 (2018).

2. Seebens, $H$. et al. No saturation in the accumulation of alien species worldwide. Nat. Commun. 8, 14435 (2017)

3. Vilà, M. et al. Ecological impacts of invasive alien plants: a meta-analysis of their effects on species, communities and ecosystems. Ecol. Lett. 14, 702-708 (2011).

4. Elton, C. S. The Ecology of Invasion by Animals and Plants (Univ. of Chicago Press, 1958).

5. Kuebbing, S. E. \& Nunez, M. A. Invasive non-native plants have a greater effect on neighbouring natives than other non-natives. Nat. Plants 2, 16134 (2016).

6. Golivets, M. \& Wallin, K. F. Neighbour tolerance, not suppression, provides competitive advantage to non-native plants. Ecol. Lett. 21, 745-759 (2018).

7. Zhang, Z. \& van Kleunen, M. Common alien plants are more competitive than rare natives but not than common natives. Ecol. Lett. 22 1378-1386 (2019)

8. White, E. M., Wilson, J. C. \& Clarke, A. R. Biotic indirect effects: a neglected concept in invasion biology. Divers. Distrib. 12, 443-455 (2006)

9. Sotomayor, D. A. \& Lortie, C. J. Indirect interactions in terrestrial plant communities: emerging patterns and research gaps. Ecosphere 6, art103 (2015).

10. Aschehoug, E. T. \& Callaway, R. M. Diversity increases indirect interactions, attenuates the intensity of competition, and promotes coexistence. Am. Nat. 186, 452-459 (2015)

11. Feng, Y. \& van Kleunen, M. Phylogenetic and functional mechanisms of direct and indirect interactions among alien and native plants. J. Ecol. 104, 1136-1148 (2016).

12. Stotz, G. C. et al. Not a melting pot: plant species aggregate in their non-native range. Glob. Ecol. Biogeogr. 29, 482-490 (2019).

13. Wardle, D, A. \& Peltzer, D. A. Impacts of invasive biota in forest ecosystems in an aboveground-belowground context. Biol. Invasions 19 3301-3316 (2017).

14. Kulmatiski, A., Beard, K. H. \& Stark, J. M. Soil history as a primary control on plant invasion in abandoned agricultural fields. J. Appl. Ecol, 43, 868-876 (2006).

15. Simberloff, D. \& Von Holle, B. Positive interactions of nonindigenous species: invasional meltdown? Biol. Invasions 1, 21-32 (1999).

16. Simberloff, D. Invasional meltdown 6 years later: important phenomenon, unfortunate metaphor, or both? Ecol. Lett. 9, 912-919 (2006).

17. Braga, R. R., Gómez-Aparicio, L., Heger, T., Vitule, J. R. S. \& Jeschke, J. M. Structuring evidence for invasional meltdown: broad support but with biases and gaps. Biol. Invasions 20, 923-936 (2018).

18. Maynard, D. S., Miller, Z. R. \& Allesina, S. Predicting coexistence in experimental ecological communities. Nat. Ecol. Evol. 4, 91-100 (2020).

19. May, R. M. Will a large complex system be stable? Nature 238 413-414 (1972).

20. Godoy, O., Stouffer, D. B., Kraft, N. J. B. \& Levine, J. M. Intransitivity is infrequent and fails to promote annual plant coexistence without pairwise niche differences. Ecology 98, 1193-1200 (2017).

21. Vandermeer, J. H. The competitive structure of communities: an experimental approach with protozoa. Ecology 50, 362-371 (1969).

22. Friedman, J., Higgins, L. M. \& Gore, J. Community structure follows simple assembly rules in microbial microcosms. Nat. Ecol. Evol. 1, 0109 (2017). 
23. Case, T. J. \& Bender, E. A. Testing for higher order interactions. Am. Nat. 118, 920-929 (1981).

24. Levine, J. M., Bascompte, J., Adler, P. B. \& Allesina, S. Beyond pairwise mechanisms of species coexistence in complex communities. Nature 546, 56-64 (2017).

25. Prince, E. K., Myers, T. L., Naar, J. \& Kubanek, J. Competing phytoplankton undermines allelopathy of a bloom-forming dinoflagellate. Proc. R. Soc. B 275, 2733-2741 (2008).

26. Tilman, D. Resource Competition and Community Structure (Princeton Univ. Press, 1982).

27. Dawson, W., Fischer, M. \& van Kleunen, M. Common and rare plant species respond differently to fertilisation and competition, whether they are alien o native. Ecol. Lett. 15, 873-880 (2012).

28. Godoy, O., Valladares, F. \& Castro-Diez, P. Multispecies comparison reveals that invasive and native plants differ in their traits but not in their plasticity. Funct. Ecol. 25, 1248-1259 (2011).

29. Liu, Y. J. \& van Kleunen, M. Nitrogen acquisition of Central European herbaceous plants that differ in their global naturalization success. Funct. Ecol. 33, 566-575 (2019).

30. Holt, R. D. Predation, apparent competition, and the structure of prey communities. Theor. Popul. Biol. 12, 197-229 (1977).

31. Bever, J. D., Westover, K. M. \& Antonovics, J. Incorporating the soil community into plant population dynamics: the utility of the feedback approach. J. Ecol. 85, 561-573 (1997).

32. Kulmatiski, A., Beard, K. H., Stevens, J. R. \& Cobbold, S. M. Plant-soil feedbacks: a meta-analytical review. Ecol. Lett. 11, 980-992 (2008).

33. Lekberg, Y. et al. Relative importance of competition and plant-soil feedback, their synergy, context dependency and implications for coexistence. Ecol. Lett. 21, 1268-1281 (2018)

34. Latz, E. et al. Plant diversity improves protection against soil-borne pathogens by fostering antagonistic bacterial communities. J. Ecol. 100, 597-604 (2012).

35. Kardol, P., Cornips, N. J., van Kempen, M. M. L., Bakx-Schotman, J. M. T. \& van der Putten, W. H. Microbe-mediated plant-soil feedback causes historical contingency effects in plant community assembly. Ecol. Monogr. 77, $147-162$ (2007).

36. Dawson, W., Schrama, M. \& Austin, A. Identifying the role of soil microbes in plant invasions. J. Ecol. 104, 1211-1218 (2016).

37. Callaway, R. M., Thelen, G. C., Rodriguez, A. \& Holben, W. E. Soil biota and exotic plant invasion. Nature 427, 731-733 (2004)

38. Ke, P. J. \& Wan, J. Effects of soil microbes on plant competition: a perspective from modern coexistence theory. Ecol. Monogr. 90, e01391 (2020).

39. Kuebbing, S. E., Classen, A. T., Call, J. J., Henning, J. A. \& Simberloff, D Plant-soil interactions promote co-occurrence of three nonnative woody shrubs. Ecology 96, 2289-2299 (2015).

40. Callaway, R. M. et al. Novel weapons: invasive plant suppresses fungal mutualists in America but not in its native Europe. Ecology 89, 1043-1055 (2008).

41. Darwin, C. On the Origin of Species (J. Murray, 1859).

42. Keane, R. M. \& Crawley, M. J. Exotic plant invasions and the enemy release hypothesis. Trends Ecol. Evol. 17, 164-170 (2002).

43. Mangla, S. \& Callaway, R. M. Exotic invasive plant accumulates native soil pathogens which inhibit native plants. J. Ecol. 96, 58-67 (2008).

44. Saul, W. C. \& Jeschke, J. M. Eco-evolutionary experience in novel species interactions. Ecol. Lett. 18, 236-245 (2015)

45. van Kleunen, M. et al. Global exchange and accumulation of non-native plants. Nature 525, 100-103 (2015).

46. Pyšek, P. et al. Naturalized alien flora of the world. Preslia 89, 203-274 (2017).

47. Essl, F. et al. Drivers of the relative richness of naturalized and invasive plant species on Earth. AoB PLANTS 11, plz051 (2019).

48. Seebens, $H$. et al. Global rise in emerging alien species results from increased accessibility of new source pools. Proc. Natl Acad. Sci. USA 115, E2264-E2273 (2018).

49. Adler, P. B. et al. Competition and coexistence in plant communities: intraspecific competition is stronger than interspecific competition. Ecol. Lett. 21, 1319-1329 (2018)

50. Mangan, S. A. et al. Negative plant-soil feedback predicts tree-species relative abundance in a tropical forest. Nature 466, 752-755 (2010)

51. Dal Co, A., van Vliet, S., Kiviet, D. J., Schlegel, S. \& Ackermann, M. Short-range interactions govern the dynamics and functions of microbial communities. Nat. Ecol. Evol. 4, 366-375 (2020).

52. Reinhart, K. O., Packer, A., Van der Putten, W. H. \& Clay, K. Plant-soil biota interactions and spatial distribution of black cherry in its native and invasive ranges. Ecol. Lett. 6, 1046-1050 (2003).

53. Liu, H. \& Stiling, P. Testing the enemy release hypothesis: a review and meta-analysis. Biol. Invasions 8, 1535-1545 (2006).

54. Zhang, Z. et al. Contrasting effects of specialist and generalist herbivores on resistance evolution in invasive plants. Ecology 99, 866-875 (2018).
55. Chun, Y. J., van Kleunen, M. \& Dawson, W. The role of enemy release, tolerance and resistance in plant invasions: linking damage to performance. Ecol. Lett. 13, 937-946 (2010).

56. Dickie, I. A. et al. The emerging science of linked plant-fungal invasions. New Phytol. 215, 1314-1332 (2017).

57. Shipunov, A., Newcombe, G., Raghavendra, A. K. H. \& Anderson, C. L. Hidden diversity of endophytic fungi in an invasive plant. Am. J. Bot. 95, 1096-1108 (2008).

58. Hardoim, P. R. et al. The hidden world within plants: ecological and evolutionary considerations for defining functioning of microbial endophytes. Microbiol. Mol. Biol. Rev. 79, 293-320 (2015).

59. Busby, P. E., Peay, K. G. \& Newcombe, G. Common foliar fungi of Populus trichocarpa modify Melampsora rust disease severity. New Phytol, 209, 1681-1692 (2016),

60. Großkopf, T. \& Soyer, O. S. Synthetic microbial communities. Curr. Opin. Microbiol. 18, 72-77 (2014)

61. Divišek, J. et al. Similarity of introduced plant species to native ones facilitates naturalization, but differences enhance invasion success. Nat. Commun. 9 , 4631 (2018).

62. Feng, Y., Fouqueray, T. D., van Kleunen, M. \& Cornelissen, H. Linking Darwin's naturalisation hypothesis and Elton's diversity-invasibility hypothesis in experimental grassland communities. J. Ecol. 107, 794-805 (2019).

63. Li, S. P. et al. The effects of phylogenetic relatedness on invasion success and impact: deconstructing Darwin's naturalisation conundrum. Ecol. Lett. 18, 1285-1292 (2015).

64. van Kleunen, M., Dawson, W., Bossdorf, O. \& Fischer, M. The more the merrier: multi-species experiments in ecology. Basic Appl. Ecol. 15, 1-9 (2014).

65. FloraWeb (Bundesamt für Naturschutz, 2003); http://www.floraweb.de/

66. Richardson, D. M. et al. Naturalization and invasion of alien plants: concepts and definitions. Divers. Distrib. 6, 93-107 (2000).

67. Brinkman, E. P., Van der Putten, W. H., Bakker, E.-J. \& Verhoeven, K. J. F. Plant-soil feedback: experimental approaches, statistical analyses and ecological interpretations. J. Ecol. 98, 1063-1073 (2010).

68. Rinella, M. J. \& Reinhart, K. O. Toward more robust plant-soil feedback research. Ecology 99, 550-556 (2018).

69. Zhang, Z., Liu, Y., Brunel, C. \& van Kleunen, M. Evidence for Elton's diversity-invasibility hypothesis from belowground. Ecology https://doi. org/10.1002/ecy.3187 (accepted).

70. Klindworth, A. et al. Evaluation of general $16 \mathrm{~S}$ ribosomal RNA gene PCR primers for classical and next-generation sequencing-based diversity studies. Nucleic Acids Res. 41, el (2013).

71. Orgiazzi, A. et al. Unravelling soil fungal communities from different Mediterranean land-use backgrounds. PLoS ONE 7, e34847 (2012)

72. Martin, M. Cutadapt removes adapter sequences from high-throughput sequencing reads. EMBnet $J .17,10-13$ (2011).

73. Callahan, B. J. et al. DADA2: high-resolution sample inference from Illumina amplicon data. Nat. Methods 13, 581-583 (2016).

74. Nilsson, R. H. et al. The UNITE database for molecular identification of fungi: handling dark taxa and parallel taxonomic classifications. Nucleic Acids Res. 47, D259-D264 (2018)

75. Nguyen, N. H. et al. FUNGuild: an open annotation tool for parsing fungal community datasets by ecological guild. Fungal Ecol. 20, 241-248 (2016).

76. R: A language and environment for statistical computing v.3.6.1 ( $R$ Foundation for Statistical Computing, 2019); http://www.R-project.org/

77. Pinheiro, J., Bates, D., DebRoy, S., Sarkar, D. \& R Core Team. nlme: Linear and nonlinear mixed effect s models. R package version 3.1-140 (2019). 78. Gibson, D., Connolly, J., Hartnett, D. \& Weidenhamer, J. Designs for greenhouse studies of interactions between plants. J. Ecol. 87, 1-16 (1999).

79. Aschehoug, E. T., Brooker, R., Atwater, D. Z., Maron, J. L. \& Callaway, R. M. The mechanisms and consequences of interspecific competition among plants. Annu. Rev. Ecol. Syst. 47, 263-281 (2016).

80. Hart, S. P., Burgin, J. R. \& Marshall, D. J. Revisiting competition in a classic model system using formal links between theory and data. Ecology 93, 2015-2022 (2012).

81. Zuur, A., Ieno, E., Walker, N., Saveliev, A. \& Smith, G. Mixed Effects Models and Extensions in Ecology with R (Springer, 2009).

82. Schielzeth, H. Simple means to improve the interpretability of regression coefficients. Methods Ecol. Evol. 1, 103-113 (2010)

83. Bennett, J. A. \& Klironomos, J. Mechanisms of plant-soil feedback interactions among biotic and abiotic drivers. New Phytol. 222, 91-96 (2019).

84. Oksanen, J. et al. vegan: Community Ecology Package. R package version 2.5-6 (2019).

85. Wei, T. \& Simko, V. corrplot: Visualization of a correlation matrix. R package version 0.84 (2017)

\section{Acknowledgements}

We thank L. Arnold, S. Berg, O. Ficht, M. Fuchs, S. Gommel, E. Mamonova, V.

Pasqualetto, C. Rabung, B. Rüter, B. Speißer, H. Vahlenkamp and E. Werner for practical assistance, and J. Levine and R. Rohr for early discussion. Z.Z. was funded by the China 
Scholarship Council (grant no. 201606100049) and supported by the International Max Planck Research School for Organismal Biology. Y.L. was funded by the Chinese Academy of Sciences (grant nos. Y9H1011001 and Y9B7041001).

\section{Author contributions}

Z.Z. conceived the idea. Z.Z., Y.L. and M.v.K. designed the experiment. Z.Z., Y.L. and C.B. performed the experiment. Z.Z. analysed the data and wrote the manuscript with input from all other authors.

\section{Competing interests}

The authors declare no competing interests. 
a

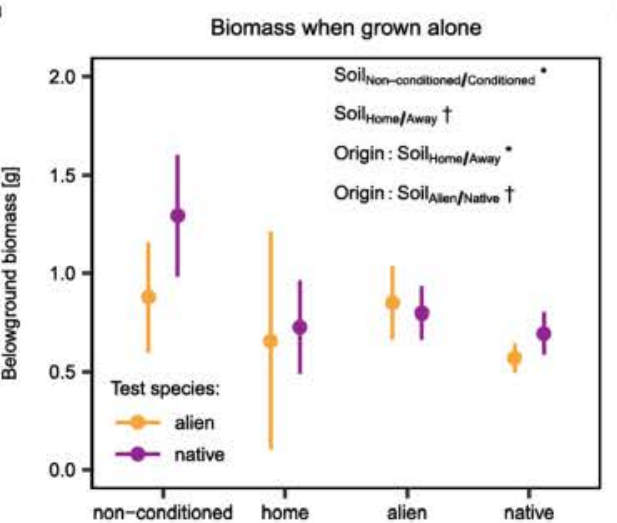

Soil treatment

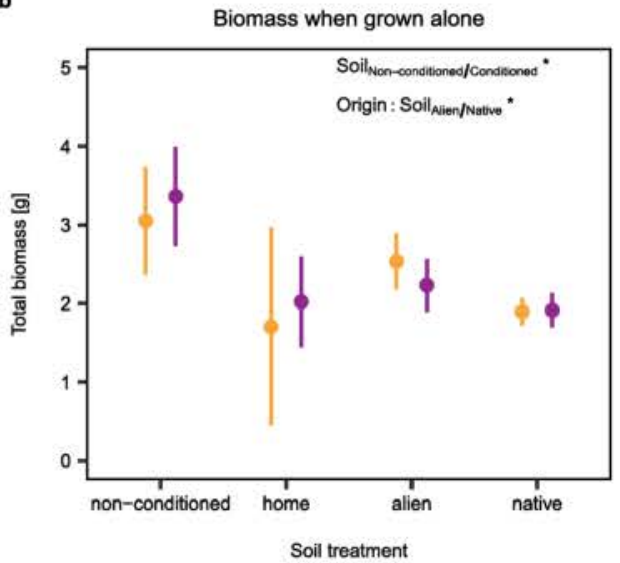

Extended Data Fig. 1 | Effects of soil-conditioning treatments on belowground and total biomass of alien (orange) and native (purple) test species that were grown alone. Mean values ( \pm SEs) were calculated based on biomass of plants grown alone. For the soil-conditioning treatments, 'non-conditioned' refers to soil that was not conditioned by any plant, 'home' to soil conditioned by the same species as the test species, and 'alien' and 'native' to soils conditioned by other species than the test species, which were alien or native, respectively. 
Bacteria (Live)

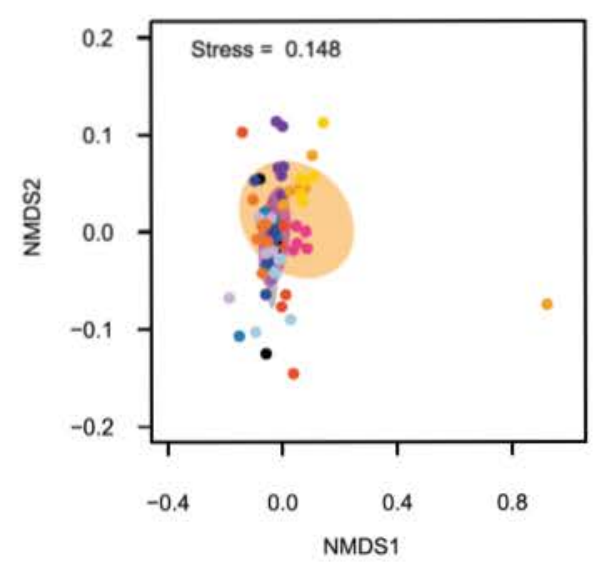

c

Fungi (Live)

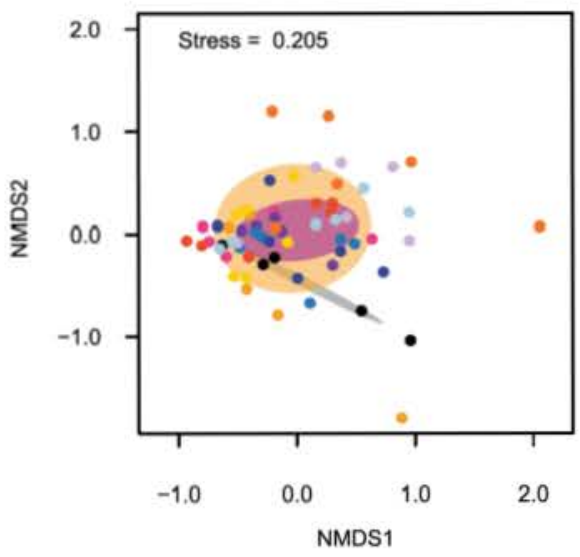

b

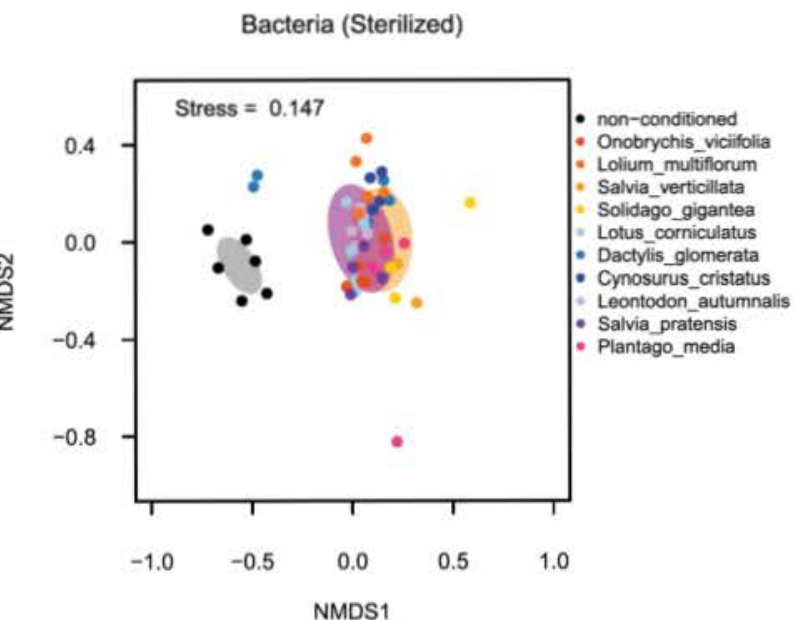

d

Fungi (Sterilized)

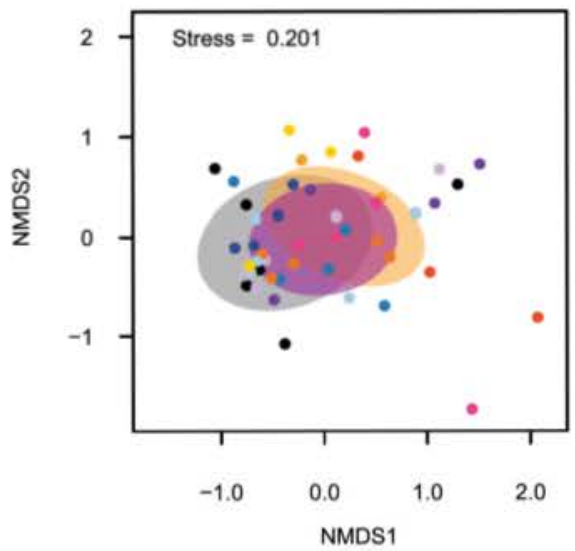

Extended Data Fig. 2 | Effects of soil-conditioning treatments on soil community compositions of bacteria and fungi. Nonmetric multidimensional scaling (NMDS) was used to visualize differences in the soil microbial communities of the plant species. Data points represent soil samples. Ellipses represent means \pm 1 SDs for soil conditioned by aliens (orange) or natives (purple), or not conditioned by plants (grey). The different colors used for the points indicate different species. Soil was either alive $(\mathbf{a}, \mathbf{c})$ or sterilized $(\mathbf{b}, \mathbf{d})$ before the conditioning treatment. 

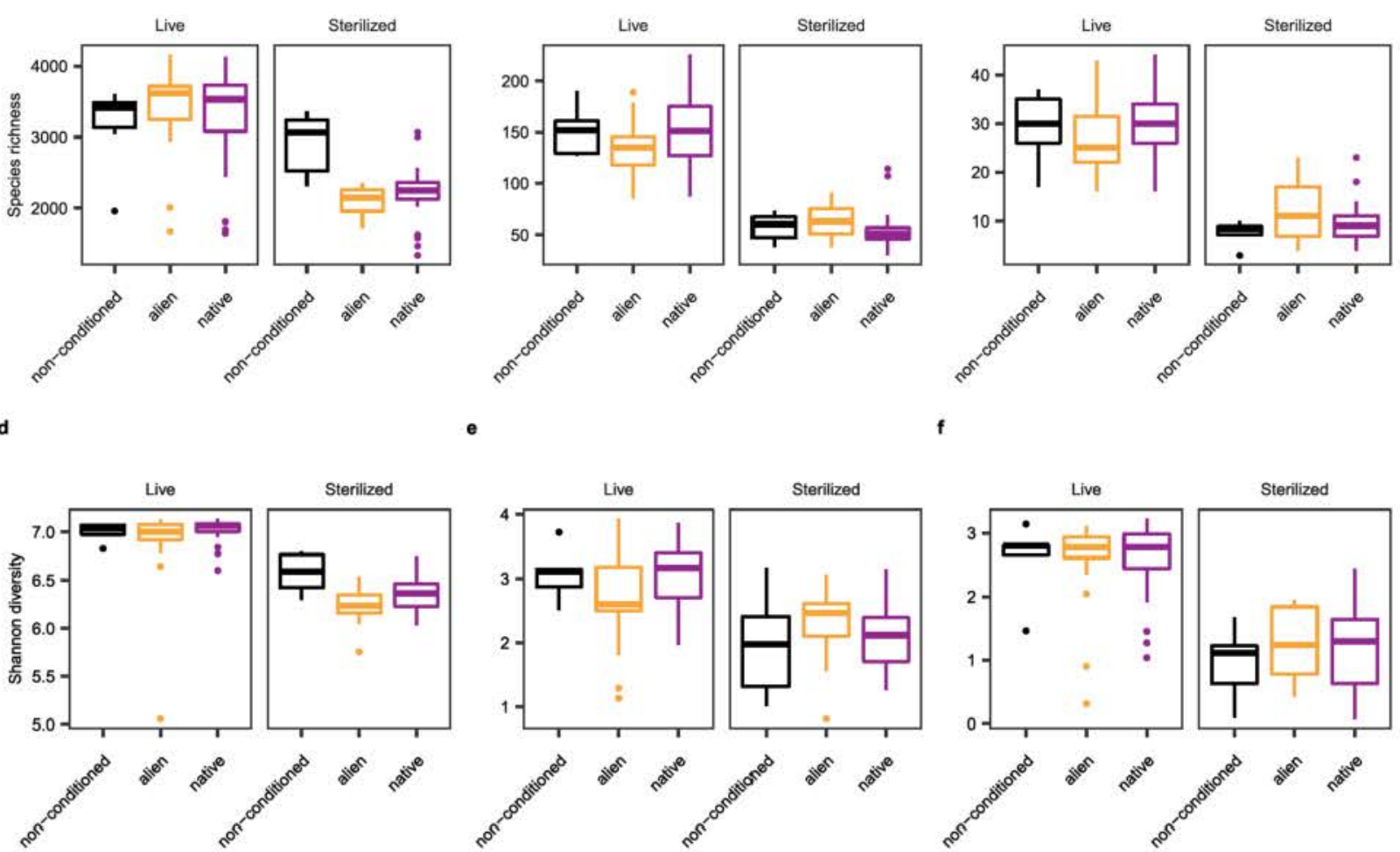

$\mathbf{g}$

Fungal pathogens

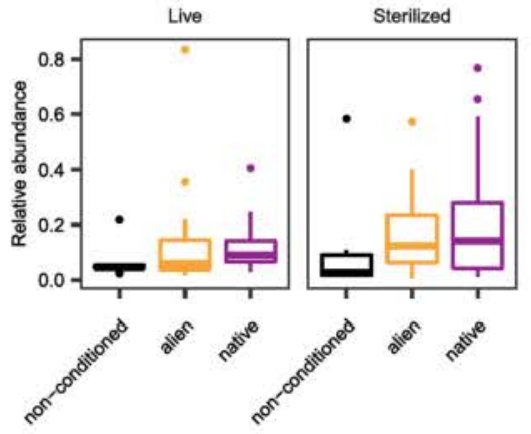

Extended Data Fig. 3 | Effects of soil-conditioning treatments on diversity of soil bacteria and fungi and relative abundance of fungal pathogens. Species richness and Shannon diversity were calculated as diversity metrics. Soil was either alive or sterilized before the conditioning treatment. 
a

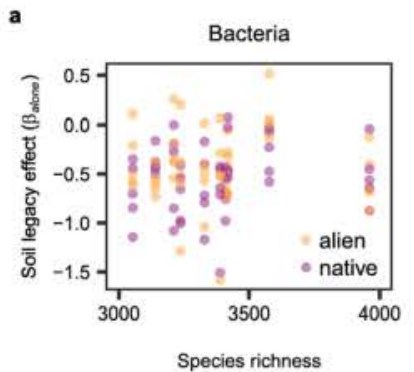

d

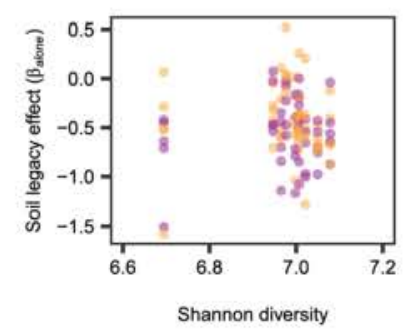

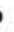
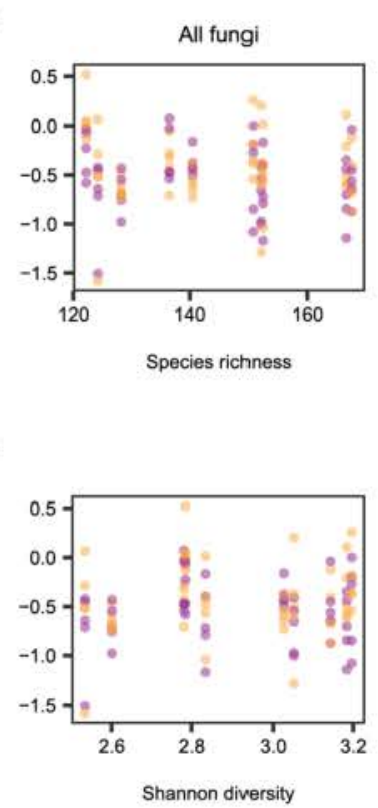

c
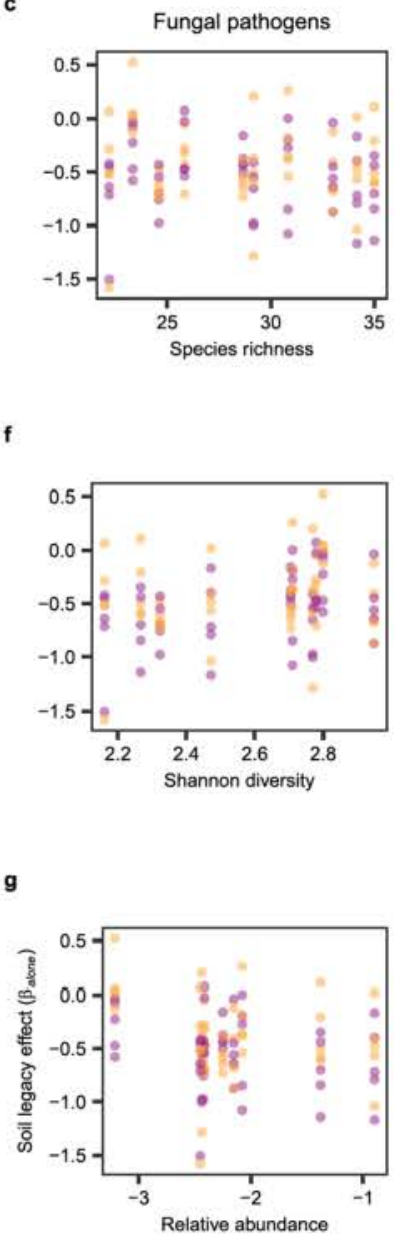

Extended Data Fig. 4 | Effects of diversity of bacteria and fungi, and relative abundance of fungal pathogens on soil-legacy effects. Purple dots represent native test species, and orange dots represent alien test species. Negative values of soil-legacy effects indicate that plants grew worse on conditioned soil than on non-conditioned soil. No significant relationship was found. Note that relative abundance of all bacteria and fungi is 1 , and thus their correlations to soil-legacy effect was not tested. 
Pathogenic endophytes

a
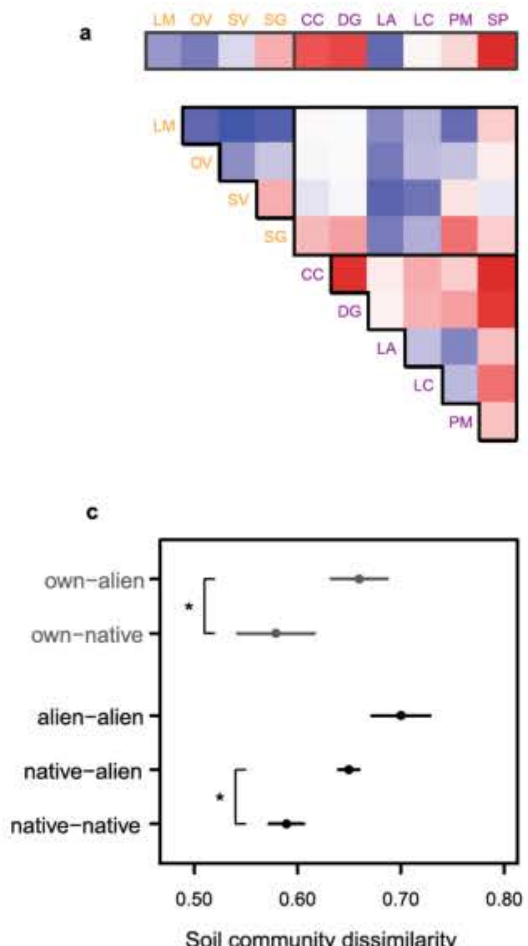

Soil community dissimilarity

e

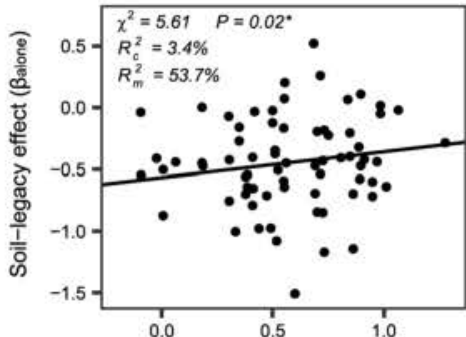

Soil community dissmilarity
Non-pathogenic endophytes
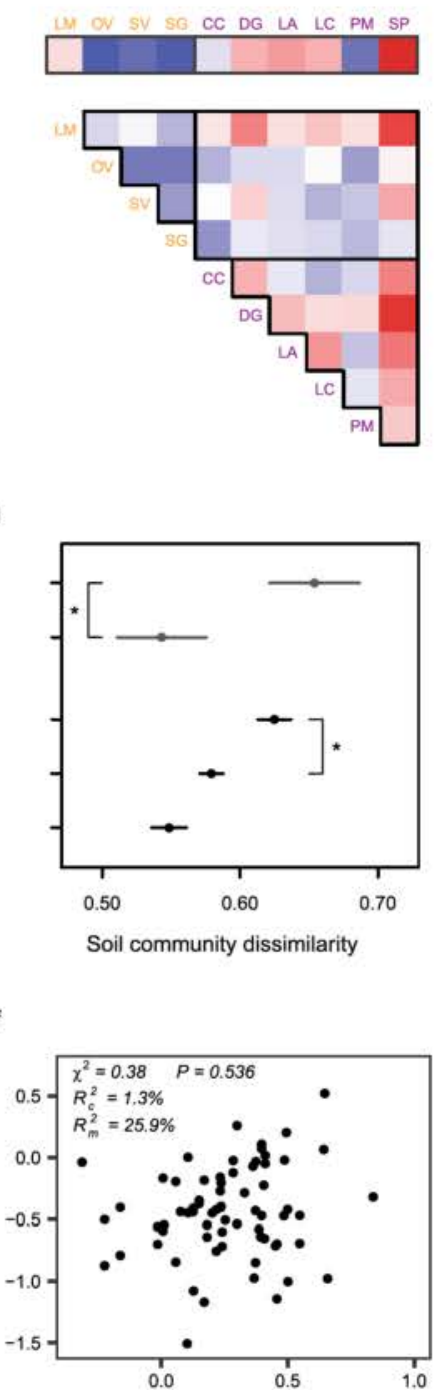

Soil community dissmilarity

Extended Data Fig. 5 | Dissimilarities of pathogenic or non-pathogenic fungal microbial communities within and between plant species and effects of soil-community dissimilarity on soil-legacy effects. a, c, e, pathogenic fungal endophyte communities; $\mathbf{b}, \mathbf{d}, \mathbf{f}$, non- pathogenic fungal endophyte communities. See Fig. 4 for detailed descriptions of a-d. See Fig. 5 for detailed descriptions of e, $\mathbf{f}$. 
b

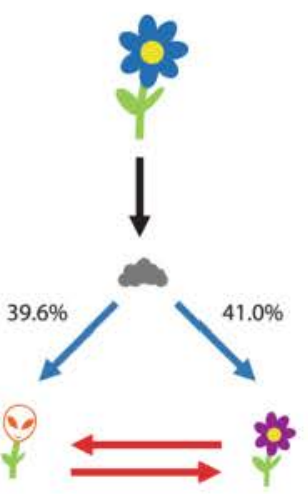

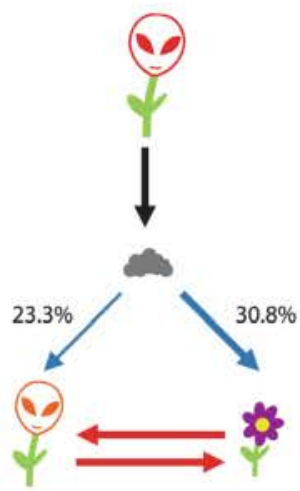

Extended Data Fig. 6 | Graphical summary of effects of soil-conditioning plants on competitive outcomes between alien and native plants. a, In pairwise competition, aliens and natives had similar aboveground biomass when grown alone, and suppressed each other equally, as indicated by the same thickness of the red arrows. Consequently, aliens were as competitive as natives (that is natives had similar aboveground biomass when in competition). b, soil conditioned by natives suppressed later aliens and natives equally, as indicated by the same thickness of the blue arrows. Consequently, soil conditioned by natives did not change the competitive outcomes. c, soil conditioned by aliens suppressed later aliens less than natives, as indicated by the thinner blue arrow towards aliens. Consequently, aliens changed the competitive outcomes, favoring later aliens over natives. Effects of soil conditioned by plants on strength of competition (that is red arrows) are not shown, as they did not change competitive outcomes between alien and native plants (for example see Fig. 3c). 
a
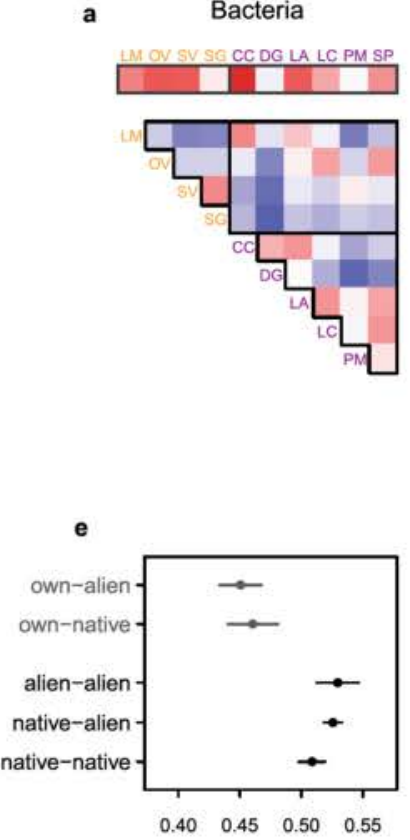

Soil community dissimilarity b

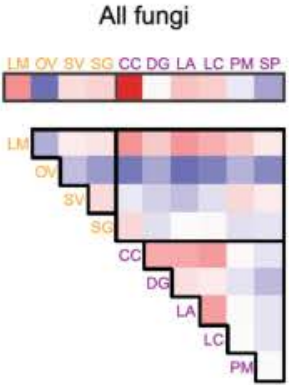

f

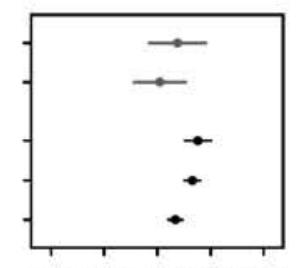

$\begin{array}{lllll}0.50 & 0.60 & 0.70 & 0.80 & 0.90\end{array}$

Soil community dissimilarity
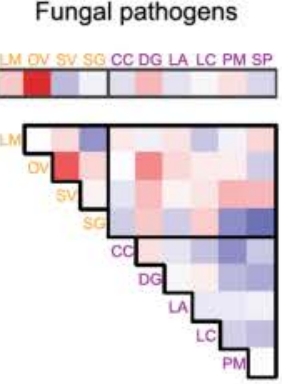

g

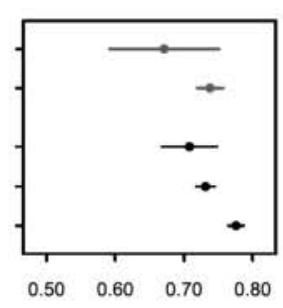

Soil community dissimilarity d
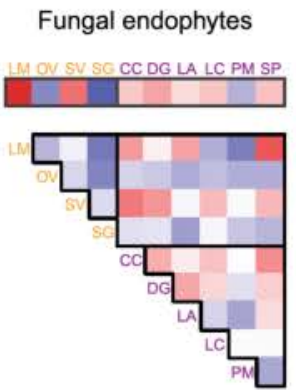

k

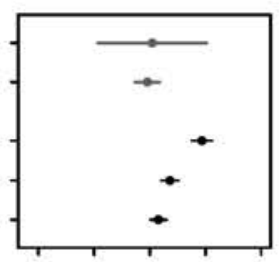

$\begin{array}{lllll}0.60 & 0.70 & 0.80 & 0.90 & 1.00\end{array}$

Soil community dissimilarity

Extended Data Fig. 7 | Dissimilarities of soil communities within and between species, when sterilized field soil was used as inoculum. a, e, bacterial communities; b, f, fungal communities, $\mathbf{c}, \mathbf{g}$, fungal pathogen communities; d, h, fungal endophyte communities. See Fig. 4 for detailed descriptions. 